Meta

Journal des traducteurs

Translators' Journal

\title{
From Functional Grammar and Speech-Act Theory to Structure of Meaning: A Three-Dimensional Perspective on Translating
}

\section{Chunshen Zhu}

Volume 41, numéro 3, septembre 1996

URI : https://id.erudit.org/iderudit/004645ar

DOI : https://doi.org/10.7202/004645ar

Aller au sommaire du numéro

Éditeur(s)

Les Presses de l'Université de Montréal

ISSN

0026-0452 (imprimé)

1492-1421 (numérique)

Découvrir la revue

Citer cet article

Zhu, C. (1996). From Functional Grammar and Speech-Act Theory to Structure of Meaning: A Three-Dimensional Perspective on Translating. Meta, 41(3), 338-355. https://doi.org/10.7202/004645ar
Résumé de l'article

L'auteur soutient que la comparaison textuelle est d'importance vitale en traductologie; il faut donc prioritairement identifier les propriétés textuelles comparables et qui devraient être comparées. Pour entamer sa recherche sur la nature tri-stratale du langage en création textuelle, l'auteur débute par une comparaison entre la grammaire fonctionnelle et la théorie des actes de langage. L'examen révèle que le sens textuel est une structure tridimensionnelle et il permet, par conséquent, la création d'un modèle plus compréhensif : une "structure du sens" (Structure of Meaning (SOM)). Ce modèle offre une perspective fonctionnelle sur la création textuelle en traduction, sur une base comparative, en examinant chacune des trois dimensions : la composition linguistique, la dynamique interactionnelle et l'impact esthétique. L'observation des relations proportionnelles entre les trois dimensions d'une "structure de sens" a dévoilé de nouvelles informations sur des questions telles que le genre, la forme et le contenu, l'information et l'effet dans l'élaboration de textes en langue cible. 


\title{
FROM FUNCTIONAL GRAMMAR AND SPEECH-ACT THEORY TO STRUCTURE OF MEANING: A THREE-DIMENSIONAL PERSPECTIVE ON TRANSLATING ${ }^{1}$
}

\author{
CHUNSHEN ZHU \\ National University of Singapore, Singapore
}

\begin{abstract}
Résumé
L'auteur soutient que la comparaison textuelle est d'importance vitale en traductologie; il faut donc prioritairement identifier les propriétés textuelles comparables et qui devraient être comparées. Pour entamer sa recherche sur la nature tri-stratale du langage en création textuelle, l'auteur débute par une comparaison entre la grammaire fonctionnelle et la théorie des actes de langage. L'examen révèle que le sens textuel est une structure tridimensionnelle et il permet, par conséquent, la création d'un modèle plus compréhensif: une «structure du sens» (Structure of Meaning (SOM)). Ce modèle offre une perspective fonctionnelle sur la création textuelle en traduction, sur une base comparative, en examinant chacune des trois dimensions : la composition linguistique, la dynamique interactionnelle et l'impact esthétique. L'observation des relations proportionnelles entre les trois dimensions d' une "structure de sens» a dévoilé de nouvelles informations sur des questions telles que le genre, la forme et le contenu, l'information et l' effet dans l'élaboration de textes en langue cible.
\end{abstract}

\begin{abstract}
The article holds that textual comparison is of vital importance in translation studies One of the key issues therefore is to identify the textual properties that are comparable and should be compared. In its investigation into the tri-stratal nature of language use in text formation, the article starts with a comparison of functional grammar and speech act theory. The investigation has led to a perception that textual meaning is a three-dimensional structure and hence to the production of a more comprehensive model, Structure of Meaning (SOM). The model is meant to offer a functional perspective on text formation in the process of translating, on a comparative basis, by examining one by one the three constituent dimensions, i.e., linguistic composition, interactional dynamic and aesthetic impact. The observation of proportionate relationships between the three dimensions of a Structure of Meaning has thrown some new light on issues such as genre, form and content, information, and effect, in the formation of the target language text.
\end{abstract}

Translation, in general, is believed to be conducted from one language into another; but in particular, it is an effort to generate a new text in the target language (TL) from one already existing in the source language (SL) - that is, its performance can be more readily perceived through comparison between texts than between languages. A translation is held accountable more for the world presented in the original text $(i . e$. , the real world filtered through or even twisted, if you like, by the grids of the author's mind and the language used) rather than the general truth of the real world itself, although some critics, as Holmes (1988: 10) observes, have abandoned "the measuring stick of the original." A TL text may in its own right possess a structure distinct from that of the original, it must be 
comparable to the SL text, albeit that the degree of comparability may vary from genre to genre.

But what factors are to be taken into account in a comparative study of the texts in question? Richards (1953) first drew our attention to the "comparing activity" illustrated by the "simplest" room/box comparison in length, breadth and height, with a suggestion of seven dimensions or functions to consider in linguistic comprehension. This version, already increased from his previous one of six dimensions, was later extended to eight (Russo 1989: 137). Another case, on a different basis but equally instructive, can be found in Coulthard's (1985: 24-25) more recent observation of the increase in categories in the attempt at classification of illocutionary acts: from Searle's five macro-classes to Leech's six and Stiles' eight categories.

The numbers do nothing magical and should not be our present interest, of course. But what they reveal is that classification can grow almost indefinitely in delicacy in line with the increasing sophistication of a theory or of the studies in a specific field. Also they carry a warning: in every single use of a language there can be as many aspects to consider as one may wish. But in translation studies we certainly do not wish to start with comparison and end up in mere classifying. Comparison is of primary importance in translation studies but should be kept at the most fundamental level relevant to the general purpose of translating activity. It is in this connection that we find that three-tier descriptions of language and language use offered by a Hallidayan functional grammar and speech act theory can serve as an initial framework for comparison between the SL and the TL texts. The coincidence of the number alerts us only to the fact that a language, in its textual realization, can be fruitfully explored on the whole as a structure of just three primary dimensions, each containing further observable "facets." A comparison of two structures as such (in its simplest and most straightforward manner) is thus a cubic one similar to comparison of solid spaces. This understanding puts translation comparison on a more definite as well as comprehensive basis while offering adequate flexibility to meet diverse demands in particular cases. The present research is concerned with the establishment of a cubic model as such, which is referred to as STRUCTURE OF MEANING (SOM), and with the investigation into its applicability offered as a guide (but not a rule) for the practical purposes of textual comparison in translation between English and Chinese.

\section{FUNCTIONAL GRAMMAR AND TRANSLATION}

Halliday $(1973,1978,1985)$ identifies in his systemic-functional theory the tri-stratal nature of linguistic systems, which consists of three principal systems roughly glossed as follows:

Semantic system (meaning);

Lexicogrammatical system (wording);

Phonological/graphological system (substance).

Halliday further specifies three components of the semantic system:

Ideational (experiential and logical): the content or meaning that embodies the language user's experience of the world and his/her relation with that world as he/she perceives it, and transitivity that carries the logical mechanism of meaning which may be different from the surface-structures of traditional grammar;

Interpersonal: the mood, modality, person and intonational components of the syntactic form, which express the language user's attitudes and realize his / her position and role in the communication with other users, it is "both interactional and personal" (Halliday 1973: 107); 
Textual: which performs the enabling function of text formation or creation, relating the text to the context (the situation and the preceding text) as well as giving it an independent and unique "textuality."

This functional perspective serves to explain the nature of language. In Halliday's (1978: 48) words: "language is in fact structured along these three dimensions." Together with the situational determinants which have to do with subject matter, participants and language performance, i.e., field, tenor and mode, the most basic features of this model can be put in a diagram as figure 1 below. Within the semantic system, as Halliday has rightly pointed out, the textual component, which performs the "enabling function," is distinct from the other two (i.e. ideational and interpersonal), since "language can effectively express ideational and interpersonal meanings only because it can create text" (Halliday 1978: 130).

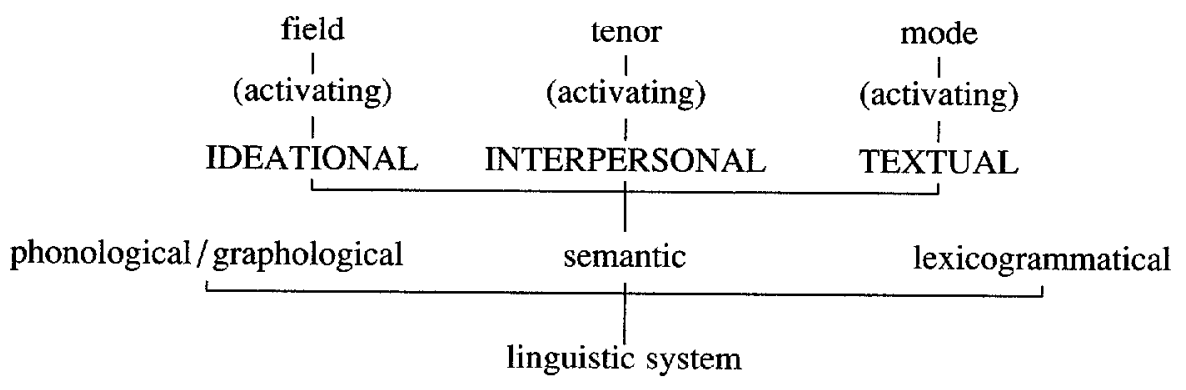

Figure 1

Thus so far as written text is concerned, the lexicogrammatical stratum appears as much distinct from the other two within the linguistic system as the textual within the semantic, because it is the lexicogrammatical that provides the primary material means ("wording") for the textual function of the semantic system to create text. As Halliday observes: "It is the function of the lexicogrammatical stratum [...] to form a single integrated structure that represents all components simultaneously" (Halliday 1978: 128). The secondary means is the phonological/graphological stratum, whose significance in the written forms of a language is by no means negligible either.

The creation of text can be inspired primarily for a transactional purpose of conveying ideational information about the world, or can be occasioned by an interactional need to establish and maintain certain interpersonal (social) relationships. And as McCarthy (1991: 136-137) has argued, no matter which of the two elements (transactional or interactional) is emphasized in a typical stretch of communication, it is usually complemented by the other so as to perform a normal social function, a point which seems to be adequately borne out by natural data. In interpreting a text for translation, therefore, we have to observe all these systems simultaneously, because the text as the product of a text-creating process represents all of them at the same time. But when tracing the process of translating itself, we may find that such a decision-making process appears to be more successive and transactional in nature. In other words, activated (inspired or called upon) by the field (e.g. the value of the SL text appreciated or deemed marketable in the TL social environment), one has something to translate (the ideational content); and more or less simultaneously determined by the tenor, one starts to anticipate the target audience, which may be different socially from that of the SL text (the interpersonal consideration). Then, with rhetorical modes made available by the lexicogrammatical and phonological/graphological 
systems of the target language, one sets to and creates a relevant text (exercising the textual function).

One fact, significant in writing and translating alike, is to be noted though, that at the stage of text creation one is still governed, through the constraints of register, jointly by the situational factors of field, tenor and mode. That is why the meaning finally produced in the text, an actualization of the meaning potential of the language's semantic system, may still be somewhat different from the original ideational and interpersonal meanings that have triggered off the process.

This insight into differences between the analysis of textual products and the analysis of textual processes is of vital importance to translation. That is to say, in analyzing the SL original, which is already in existence, the translator should ideally speculate simultaneously on the three dimensions of the text for a comprehensive interpretation. And in the process of creating a TL text, the translator may have to switch the focus of attention between dimensions; what is more, the situational factors that affect the translator at this stage can very well acquire some elements typical of the socio-cultural context of the target language. From the systemic-functional framework we may work out a preliminary model of the writing-translating process as shown in figure 2 below.

From figure 2 it will be clear that in the process of writing, the primary intention or motivation that has stimulated the writing (whatever it has been, transactional or interactional) is being materialized textually, with ideas and experience clarified and structured through the use of language, as the three functions work simultaneously on the actual process of writing. And it is in this sense that we say that the performance of textual function involves the writers' experience of the language used, as opposed to the experience of the external world and the internal world of their (sub)consciousness in the ideational domain. And in translating, the translator's experience of the target language may be very different from that of the original author, although the translator may succeed in approximating the author's experience of these worlds. It should be pointed out, though, that a Hallidayan description of translation as such does not have much to offer about the issue of intention and effect; hence, as it stands, it is not extensive enough to cover the aesthetic domain of translation in general.

\section{SPEECH ACT THEORY AND TRANSLATION}

Another three-dimensional theory, which supplements our perception of translation by dealing with intention, effect and communicative achievement in language use, is speech act theory. As Austin puts it, "we have three, if not more, different senses or dimensions of the 'use of a sentence'..." (1975: 109). The three dimensions, or, types of speech act, are:

Locutionary act: a linguistic act of saying something with an identifiable propositional meaning; Illocutionary act: a linguistic act in saying something valid in a conventional communicative context, which acquires a certain conventional, thus cultural, force to effect the communication by $e . g$. securing uptake, inviting a response, etc.;

Perlocutionary act: a social act by saying something which would produce effects (intended or unintended) upon the listener's feelings, thoughts or actions.

The perlocutionary act, not conventional in nature, is a consequence of the other two acts. It can take the form of achievement or failure of a perlocutionary object such as convincing, persuading or surprising, or the form of production of a perlocutionary sequel without using a conventional illocutionary formula (Austin 1975: 118). 


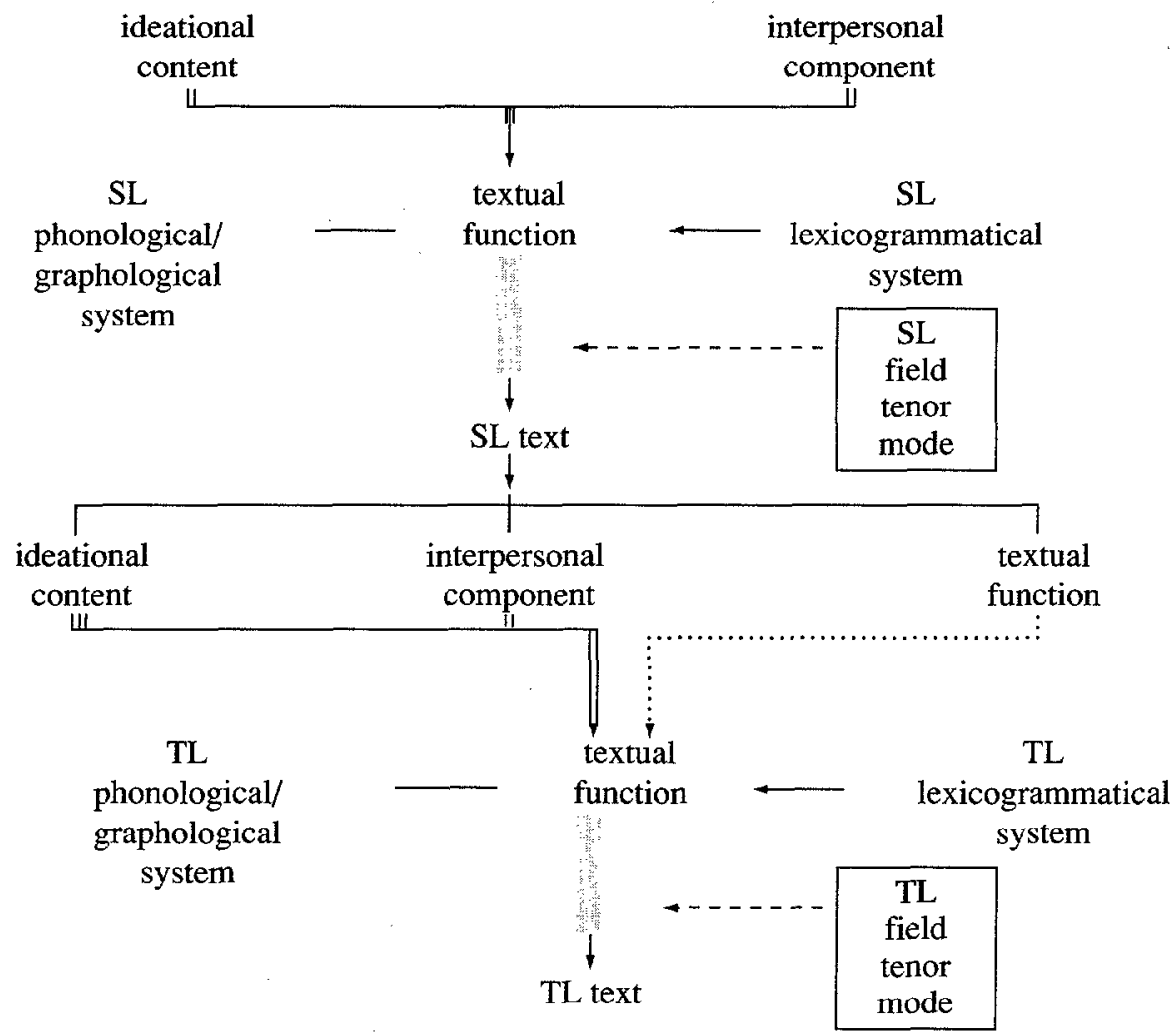

Symbols:
(1) $\Psi_{\|}$direct presence;
(2) indirect presence;
(3) text creating;
(4)
by means of;
(5) $†$ derived simultaneously;
(6) - . . determining through the register

Figure 2

Speech act theory brings under focus our concern with reference/"meaning" conventions, and their consequence in language use. These can be roughly summed up under two categories: cultural and individual. On the one hand, as the collective title of Austin's William James Lectures suggests, speech act theory, especially the illocutionary component, has a lot to do with language use in its cultural situation, because how to do things with... manifests itself as a basic cultural pattern. On the other hand, the speech act takes into account the individuality of language use as well. As Coulthard (1985: 20) points out, a potential investigation of the perlocutionary could lead to another pattern, 
that is, how to achieve things through... The pattern is inclined to be more individual than cultural, as it deals with effects on feelings, thoughts and/or behaviour.

It is in respect of individuality in a broader sense, i.e. individual intention and interpretation, that we notice an interesting shift of emphasis in the evolution of speech act theory, which has been observed by Coulthard (ibid.): for Austin, the illocutionary force lies in the successful realization of the speaker's intention, while for Searle it is a product of the listener's interpretation. Coulthard goes on to argue that to discover the speaker's intention has long been regarded by literary critics as a "fruitless endeavour," and:

those analysing language in use have discovered, there is, fortunately, no real need to concern oneself with the speaker's intention because interaction proceeds according to the listener's interpretation of the force of an utterance.

Communicationally-oriented theories have given rise in translation studies to some reader-centred conceptions such as Dynamic Equivalence (e.g. Nida 1964: 176-177, Nida and Taber 1969: 22-23), one of this century's echoes to Francis Newman's argument that "the educated but unlearned public is the only rightful judge [of the taste of a translation]" (quoted in Bassnett-McGuire 1980: 9; for the opposing argument, see e.g. Lefèvre 1975: 3). It is interesting, nevertheless, to point out that by following this argument of reader-centredness, or in other words Edmondson's "hearer-knows-best" principle (quoted in Coulthard 1985), one is bound to arrive, paradoxically, at a translator-centred view of translation. That is to say, in reading the SL text, it is the interpretation by the translator, as an SL reader, that matters; while in writing the TL version, as a TL writer, the translator should resign him/herself to the prospect that both the author's and his / her own intentions are to be left to the mercies of the TL reader's interpretation and should not be of a real concern, as it were. To put it in a less pleasant way, the reader is the customer, is God, and not only does God know better, but as Robert Browning wittily remarks, "when I wrote these lines, only God and I knew their meaning. Now only God knows"!

A reiteration of the distinction made by Rodway in his The Craft of Criticism (1982: $175-176,184-185$ ) seems necessary at this juncture. That is, the so-called "speaker/author's intention" which has caused dissent among language analysts and indeed literary critics, as Coulthard has referred to, is a kind of "intentionalism," for the fallaciousness of which Rodway (ibid.) has given seven reasons. Intentionalism as such means deriving the speaker/author's intention from external, non-discoursal data (e.g. from the author or from scholarship), and in consequence may be quite irrelevant to the textual reality an analyst or critic is dealing with. So it is another kind of intention, the internal intention, or purport as termed by Rodway, which is implied or evidenced by the discoursal arrangements of the text, that should engage our attention throughout our analysis of a text. This is essential not only to critical appreciation in literary scholarship, but also to a wholesome understanding of the relationship between illocutionary force and perlocutionary effect in discourse analysis.

Such a perception of intention helps to furnish an aesthetic dimension to language studies as well as providing a linguistic basis for literary criticism. It also explains why, as a matter of fact, the author's intention, internal of course, has never faded from literary criticism and stylistics, and is always on the translator's mind. Halliday has argued rightly and convincingly for the importance of "motivation" in his stylistic analysis of William Golding's The Inheritors:

Foregrounding [...] is prominence that is motivated. [...] Where [a linguistic] function is relevant to our interpretation of the work, the prominence will appear as motivated. (Halliday 1973: 112) 
This bears a strong suggestion of the concern over the issue of intention in the guise of motivation, or about "the distinction between attempt and achievement" (Austin 1975: 106) of perlocutionary effects of a speech act. In translation, even the reader-centred method, i.e. Communicative Translation, proposed by Newmark (e.g. 1991: 11), takes it as one of its features or criteria to pursue the author's intention. Whatever method employed, a translation is the product of the translator's interpretation of the SL text in the translating process; but, arguably, it cannot be deemed successful or reliable if it fails to bear out, or at least recognize or acknowledge the author's apparent intention or motivation as suggested by the textual evidence and signalled by the conventions of his/her time. The translator may very well have his/her own intention in translating, which may or may not be made known to the TL audience. Moreover, the TL reader may interpret the translation in a way different from the way the TL text is supposed or hoped to be interpreted. But this goes beyond the scope of the present paper.

What speech act theory has alerted us to is the issue of author's intention. The problematic nature of discovering what the author's intention has been gives the translator more responsibility than liberty, because in most cases translation is done in line with what the translator understands as the author's intention; and the TL reader will hold $\mathrm{him} /$ her to that. A story (as against a fable with a moral), a poem, or even a metaphor (as against a simile with its intention signalled by patterns such as like..., or as... as...) frequently constitutes a perlocutionary sequel to an illocutionary intention which is too complex to be formulated with overt precision, even by the author's own speculation (see Austin 1975: 118 and Coulthard 1985: 19-20 for perlocutionary act without illocutionary formula). This, paradoxical as it may seem, points to the need for a substantial effort in textual analysis to find out what the author's intention(s) were, as indicated by the textual evidence of which Bell (1991: 163-164) has proposed seven "standards," i.e., cohesion, coherence, intentionality, acceptability, informativity, relevance and intertextuality. Only in this way can translators find themselves in a better position to see any relationships between attempt and achievement, in the SL and the TL texts respectively.

Although in identifying a speech act one's attention frequently goes no further than the contour of a sentence, a point typically illustrated by sayings such as "The speech act or acts performed in the utterance of a sentence are in general a function of the meaning of the sentence" (Searle 1969: 18), we have to resort to a greater stretch of text and communicative context in our attempt to assess the effect. For instance, we have to take into account the answer in a given situation to recognize the illocutionary force of a question. Also we have to appraise the non-linguistic aspect of reading activity, that is, the reader's response, to judge the effect(s) of a perlocutionary act, e.g. in terms of the distinction between the attempted and the achieved, or between the intended and the unintended. A case in point is to determine the illocutionary intention in second person pronouns. The distinction between $n i$ (你) and $\operatorname{nin}$ (华) in Chinese, as between tu and vous (singular) in French, can be taken as an illocutionary marker, while in English you certainly lacks such a distinguishing feature. In rendering the pronoun from English into Chinese, consequently, discourse markers have to be sought, within and without the sentence in question, for the transference of not only the correct locutionary content of number (singular or plural) but also the intended illocutionary force. Greater complication may arise when an illocutionary force functions in support of a perlocutionary effort in bringing about a change in the internal world (mind, feelings, thoughts, etc.) of the reader in, say, a literary text. This points to the need for closer analysis of what is meant by illocutionary intention and how it is retrievable in actual text, since a speech act in isolation rarely offers any substantial clue about its illocutionary force. 


\section{STRUCTURE OF MEANING (SOM): A COMPREHENSIVE THREE-DIMENSIONAL MODEL}

If the systemic-functional model is mainly concerned with the semantic structure of text, then speech act theory appears to be more about sentence in use. Although text may lack a grammatical structure to support its status in the rank scale, analysis of text as an expanded and elaborated act based on sequences of speech acts has led to the notion of text act and its use as a unit to judge translation equivalence (Hatim and Mason 1990: 78). And in our study, the pattern of "illocutionary force + information" on the sentence level can be applied to discourse analysis on the text level. (The format of letter-writing is a prime example.) So if we assume the applicability of speech act analysis on the text level, we can discern another significant link between the two models: the systemicfunctional model provides us with an insight into the mechanism of text creation in relation to language user, communication and situation, while the concept of speech act draws our attention to the illocutionary force and the perlocutionary effect of a text in actual communication, both models hinge on a three-dimensional perception of text and text creation.

At this point we are reminded of the potential three dimensional view of translation in the "faithfulness-accessibility-elegance" maxim of the discerning Yan Fu (1853-1921), a Chinese translator of authors such as T. H. Huxley at the turn of the century, who, without the sophisticated apparatus provided by modern linguistics, has notably touched upon the nature of text formation in translation, namely, to be ideationally faithful, interpersonally accessible, and textually elegant. (From the viewpoint of speech acts, it can be understood that Yan Fu's maxim was meant in theory to make his translations more appealing, persuasive and acceptable to the classically educated mandarin officialdom and intelligentsia at the time, a plausible perlocutionary attempt of this exponent of the Western new thinking.) It is interesting, anyway, to see that after nearly a century, this oriental intuitive insight finds support in the western analytic tradition.

The tri-stratal nature of language and language use can be further demonstrated by the general comparability between the two models along the three dimensions:

First, both the ideational function and the locutionary act refer to "content," or "meaning" in the traditional sense. Together they contribute to an awareness of the logical mechanism of sense-making in language use.

Secondly, both the interpersonal meaning and the illocutionary act concern themselves with communicative issues. But the interpersonal is more about "which pattern can perform what function;" thus it begins with patterns such as mood or modality, management of point of view (person), and expressiveness of intonation. The illocutionary, on the other hand, seems to work from the other end of the line: "in performing what function [e.g. informing, ordering, warning] which linguistic act is [conventionally] right;" and its effects, which are different from the perlocutionary effects, are to be verified in terms of securing uptake, taking effect, or inviting a response. The two jointly provide a communicative perception of linguistic performance in terms of role relationships in the socio-cultural context, which to a great extent determines information distribution in text formation.

In their third dimension, the two models are more complementary than similar. On the one hand, the textual, instrumental to the ideational and interpersonal (Halliday 1973: 107 ) as an enabling function, goes deeper into the linguistic potential of a language for the rhetorical modes in creating text. The performance of the textual function is thus a linguistic representation of the social interaction which should be closely connected with the context in which the text is generated; also it is an instance of application of the linguistic system of the language in which the text is written. The perlocutionary act, on the other hand, opts out of the linguistic framework and is regarded as a non-linguistic act, a conse- 
quence of the locutionary and the illocutionary which are definitely linguistic acts (Coulthard 1985: 19). How far it can stay outside the linguistic domain remains a question though, because the "persuasive and oratorical techniques" it involves, as implied by Coulthard himself (1985: 20), are by and large linguistically oriented, at least in written texts. But the consideration of non-linguistic effects on an individual's feelings, thoughts and behaviour has suggested a very significant area of attention in text analysis: the effects of textualization on the reader.

Translating starts from the analysis of one text and concludes with the creation of another, normally crossing at least two languages and cultures, a process that begins with comparison and terminates in choice. (But a translation is never finished!) "Text is meaning and meaning is choice," as Halliday (1978: 137) puts it. The systemic-functional model and speech act model, as we have seen, have offered, complementarily, some important insights into the text in creation as well as in use. But to cover the translating process proper, we are still in need of a more comprehensive model, or understanding, on the basis of those existing ones, to cater for the demand of interlingual and cross-cultural operation of choice-making in text creation. Meaning is choice and choice is threedimensional in nature, as functional grammar and speech act theory have proved. The meaning chosen in the process of writing/translating thus constitute the text as a threedimensional structure-referred in the present study as Structure of Meaning (SOM)-which in translating should be delineated in (SL) text analysis and reconstructed in (TL) text creation. In other words, at each end of the translating process there is a SOM, whose comparability and similarity determine the successfulness of the translating.

There can be no clear-cut lines between the three dimensions, each of which contains "facets" slanting in the direction of the others. The dimensions represent the emphases we put on the features of a text in one language and its translation in the other; they are not to limit our attention to one particular aspect of a linguistic fact at the expense of others. In light of this, each dimension is a part of the whole SOM, and each unit on the rank scale can potentially lend itself to comprehensive analysis as a SOM contributing to the composition of the SOM on a higher rank.

\section{LINGUISTIC COMPOSITION: THE FIRST DIMENSION OF A SOM}

In this dimension the emphasis is first of all put on the linguistic composition of a text, that is, its lexicogrammatical and phonological/graphological patterning. And secondly as a locutionary act of writing down something as a text, we must attend to its ability to make sense. Or from the translator's point of view, one must trace the ideational content activated by the field in the original text formation. To start with, one has to pay sufficient attention to the cognitive meaning and the logical relations in transitivity that make up the basic experiential sense of a text. Because syntactic sequential patterning is usually a useful and straightforward guideline to get to the most fundamental meaning of a stretch of language, analysis at this stage is generally of the wording on the sentence ("clause complex" in Halliday's terms) level or below. Translation in this linear manner can be mechanical, similar to the traditional practice as a means of foreign language acquisition. But translation has moved on.

\section{INTERACTIONAL DYNAMIC: THE SECOND DIMENSION OF A SOM}

Translation has moved into a communicative domain. Those whom it serves are no longer language pupils but reading publics of various interests. And text becomes interaction, exchange of meaning, bearer of social values rather than just a dead congregation of words. This underlines the interactive function of translation. 
In this dimension, connotative meaning presents itself frequently as a kind of interpersonal message in the sense that it depends on the reader's interpretation rather than the writer's intention to secure uptake. But on the other hand, the illocutionary forces of a text have to be explored for attitudinal messages in a conventionally agreed or recognized way. Analysis of the SL text in respect of interpersonal significance and role relationship, like analysis of the illocutionary act, is a process based on the SL convention, which should ideally find itself retained in the TL text as cultural message.

Another facet that has to be dealt with is distribution of information. This is textual in function (e.g. arrangement of Theme-Rheme patterns), but communicative in nature. It is based on the participants' assumption of shared world-knowledge, of agreed (i.e. conventional) principles of selection and organization of information, of common faith in retrievability of omissions in the process of interpretation, and of common past experience referred to in the language of the text. Even the non-structural textual devices of cohesion draw their efficiency from how much the reader has activated memory, knowledge, experience and the logic of deduction in, for instance, picking up a referent, reconstructing an ellipsis.

Translation in this dimension therefore takes the whole text into account. The method frequently used is that of Communicative Translation proposed by Newmark; the main criterion is dynamic equivalence. Translation at this stage takes it as its principal task to convey the ideational and the interpersonal information, but not necessarily the stylistic significance of the textual function. So translation has to move on.

\section{AESTHETIC IMPACT: THE THIRD DIMENSION OF A SOM}

As the word "impact" suggests, the third dimension of SOM is still interpersonal in nature. But the focus of attention here has shifted from information to effect, or, from information presentation to "information manipulation" by textual means, to match as far as possible the effect intended by the SL text and the effect actually achieved by the TL text. Approaches to the text (either SL or TL), like analyses of perlocutionary acts, are more individual than conventional. Textually, rhetorical modes and authorial techniques in this dimension can be analyzed in greater detail to reveal the author's possible intentions as understood by the translator and sensed by the reader.

This is the dimension that closes off the SOM by drawing on the resources of the other two dimensions. Let us consider the figurative use of language in a text. In order to assess its semantic significance for translation, the translator has to examine it ideationally, interpersonally as well as textually, taking into full account the situational factors that affect text formation at two stages ( $c f$. fig. 2 above). Moreover, semantic resources go beyond the boundary of the semantic system. Phonological and syntactic enactments of semantic meaning, in the form of phonaesthetic elements, marked collocation and syntactic imagery, are actually configurations of lexicogrammatical, phonological and semantic features of the language as a whole.

As for units of translation, the concept becomes rather flexible when the texts involved are seen as corresponding SOMs. On the one hand, we have to move frequently upwards from text to take into account situational activations and generic constraints. On the other hand we more often than not have to concentrate on levels downwards from text, i.e. sentence and below, to produce a matching local effect in the light of the global significance of the text. Accordingly, the method used in translation should be more faithful than Communicative Translation, but broader and more flexible than Semantic Translation by minimizing the awkwardness usually associated with the latter. In so doing the translator is conveying the original's ideational message as intactly as possible while textually involving the TL readers in, instead of merely informing them of, the effects 
intended by the SL text, using positively and actively the resources of the target language in textualization.

When translation is studied comprehensively as a three dimensional structural process it begins to stand as an academic discipline. Such a study of translation, drawing on developments in contemporary linguistics, should not be loosely based on practising translators' intuitive or empirical speculations, nor should it impose a burden of theory, to be held in contempt, disliked or feared by the translator as "a poor substitute for several years of intensive practice" (Lawendowski 1978: 265). It should instead become a reassuring link between theory and practice, providing theoretical awareness for the practice of translation. The purpose of this study, therefore, is to create a direct perspective on translation activity through the analysis of the SL text and the TL text in their corresponding dimensions of linguistic composition, interactional dynamic and aesthetic impact. Theories of various emphases are to be employed in the interest of practice-to make good translators better (nothing turns bad translators into good ones) without asking them first to become experts in linguistic theory, as some theorists may have privately hoped.

\section{RELATIONSHIPS BETWEEN THE DIMENSIONS OF A SOM}

The notion of SOM offers a perspective on translation in its linguistic, interactional and aesthetic dimensions. This is different from two-dimensional mosaic descriptions of structure, which will be more appropriately referred to as "area" (e.g. "meaning area"), or "pattern" (e.g. "sentence pattern"). In this analysis, the problematic relation between "linguistic structure" and "aesthetic structure" in literary studies, as mentioned by Drière (1957: 88), would cease to be so troublesome, as the two "structures" are treated as two complementary (instead of conflicting) constituent dimensions of a SOM.

\section{DIMENSIONS OF A SOM: A GENERIC VIEW}

What is to be translated is text. And it is the SOM of the SL text that is to be reconstructed in the TL text. But the proportions of the SOM are by no means identical in all of its dimensions in all types of texts. And it is the difference in proportionate importance of dimensions of a SOM that gives rise to the variety and diversity of text types.

A text, whatever generic group it belongs to, first of all appears as a sequence of symbols or signs on the page, i.e. words, phrases, or sentences, which forms the linear linguistic composition of its SOM. Beyond its sequential appearance, a text can be seen as a two-dimensional pattern of "form $x$ information," only to complete its SOM with a third, aesthetic dimension. The third dimension as such is the result of personal emotional involvement on the writer's part, in consequence effecting an involvement of a similar nature on the reader's part in the process of reading. If we endorse the argument of literariness, an element degrees of which are identifiable along the cline of text types in text analysis, we can see that the aesthetic dimension of a SOM runs in parallel with literariness, and may be posited as actually finding its textual realization in the latter, a question so far largely unaddressed in literary scholarship.

In this analysis, the prototypes of those text types addressed more to objective facts than to subjective emotions are generically characterized by less density of literariness and a "flatter" SOM. A "rounder" SOM will display a higher degree of literariness and a more significant aesthetic dimension. Broadly speaking, the three dimensions of a cubic SOM as such work respectively and co-operatively in a communicative situation through grammar, information processing and emotional involvement, to perform the locutionary act for a well-formed and valid sentence, the illocutionary act for an appropriate interac- 
tional force and the perlocutionary act for the intended impact (cf. Hatim and Mason 1990: 59-60).

The cubic model of SOM also means examining each text individually, by placing its features and functions in appropriate dimensions, within the framework of conventional classification of text types. A perception of text as such is of great import in translating, as a translator is dealing with individual texts most of the time. An advertisement, for instance, generally presents a SOM which is short in the first dimension (if it is terse in wording), long in the second (if it carries a great amount of message in relation to its textual size), and variable in the third (depending on the impact it makes on the receiver by means of the presentation of message). A phatic text, on the other hand, can be enormous in the first dimension but meagre in the second (apart from performing some specific social functions), and, generally, low in the aesthetic. And a poem by nature is inclined to be not sizable in the first dimension, variable in the second, but high in the aesthetic third.

So far as text classification is concerned, the traditional division between literary and non-literary languages is now under question, with the introduction of the concept of literariness and the positing of literary clines. In translation studies Newmark (1981: 127) has advocated a more functional basic distinction "between good (or effective) and bad (or ineffective) writing." Hatim and Mason, on the other hand, have warned of the danger of over-classification, arguing that classifying texts either by text feature or by text function has its built-in weakness: it tends to be too broad in the first place, and a more narrowed focus of description would either "run the risk of ending up with virtually as many text types as there are texts," or be caught in the problem of multifunctionality (1990: 138).

It is probably acceptable for a translator to be content with a general, or even noncommittal text classification, but certainly not so acceptable for him to rely on the sophisticated insights provided by genre and register considerations, in the tracing of the situational factors of field, tenor and mode (after Halliday 1978, see figures 1 and 2 above) which have a direct bearing on the actualization of the SL text. The author may claim, with witty authority, that only God knows what his work means; readers may well dodge the subtle challenge of good writing and keep to themselves whatever they have gathered from reading. The translator, however, in a sandwiched position between reader and writer, seems to be the only one who has to make every single effort to perceive the reasons behind, as well as the meaning of, the textual features in order to justify his / her own output and not to wrong either party. The model of SOM is, in a sense, designed to help reveal the ingredients of good or bad writing for inspection in translation studies. In this way the SL text and its TL counterpart can be analyzed and the process of translation studied in terms of compatibility between the two independent SOMs sustained by their individual internal relationships within the componential dimensions. All these relationships can be appropriately examined only against a dynamic background projected by the typological and generic contexts of both languages and cultures.

\section{SOM: WHERE FORM AND CONTENT MERGE}

Text typology or generic classification can by nature be regarded as one of the recent attempts to address the problematic classical dichotomy of form and content. It is a useful approach to the matter but still too general for the purpose. For linguists, it has proved inadvisable (even harmful) to divide language by textual feature into literary and non-literary types. For translators, it has been found risky to go into detailed classification by function. Classifying texts by informative message, for instance, into scientific and non-scientific types, does not help either. Typology is useful when it highlights the collective 
features of genre and register; but it can be a precarious practice if one is led to overstress certain aspects of text at the expense of others.

On the other hand, the Hallidayan system of ideational, interpersonal and textual functions and the speech act theory of locutionary, illocutionary and perlocutionary acts, as we have argued above, have pointed, respectively but correlatively, to the three primary dimensions of text, and our model of SOM is designed to incorporate the two and to extend them in dealing with the issue of translation comprehensively.

"Form" and "content," in the dualist's terms, are two distinct, or even polar and opposite components of text (see e.g. Nida and Taber 1969: 14). In the ordinary sense of the words, however, they make up only the first two dimensions of a SOM. For a text to assert its individuality, to acquire a sustainable structure, any two of the dimensions have to be connected with a third for structural stability of stylistic significance. Form and content, or linguistic composition and interactional dynamic, therefore, should be related to the third dimension of impact. In this sense we can indeed see a parallel with the "enabling" nature of Halliday's third (textual) dimension. Textual management can thus be viewed as active implementation of the author's interpersonal intention, as to it emotional and aesthetic implications have been attached.

The aesthetic impact as a dimension of the SOM in our sense therefore will not be regarded as limited, as a "minor" function of language, ranking with the phatic and the metalingual (Newmark 1981: 21), or as extreme, as the principle distinguishing poetry from prose (Drière 1957: 90-91), or as heavy-weighted, as features against semantic content and formal contour (Levy quoted in Bassnett-McGuire 1980: 5-6). At this point we have to reiterate our point made above: a text viewed from different angles can yield different proportionate relationships between the dimensions of its SOM.

The linguistic composition provides the text with a material being that makes logical sense; the interactional dynamic renders the text communicatively purposeful and the aesthetic impact ascribes individuality to the text by combining the "being," the "sense" and the "purpose" through the realization of "effect." Language and information, whatever the relation between them, have long been regarded as essential in text creation; but the aesthetic is equally indispensable with its specific contribution to shaping the text as a structure. The aesthetic quality of the text can be positive (i.e., pleasant to the senses), negative (i.e., unpleasant to the senses), or neutral. It is neither the language nor the information about the world, but the linguistic presentation of the information governed by the aesthetic that pigeonholes the text into a particular genre. And, when we consider the text in relation to its genre membership, the essence of its third dimension emerges: appropriateness to the generic requirements. Genre, fluid as it may be as a concept, provides therefore a tangible framework for textual performance.

The choice of a particular genre is actually a manifestation of communicative purposes in a certain socio-cultural situation, "ultimately a function of users" intentions" (Hatim and Mason 1990: 140). The well-writtenness of the text means, to a great extent, appropriateness on the genre level and stability on the text level. For instance, if neutrality is appropriate to a certain genre, say legal texts, then it should be obtained as the required aesthetic dimension of the SOM; and the textual stability can thus be maintained. Any other properties, positive or negative, will reduce the well-writtenness of the text of this type and upset the stability of its SOM. In texts of high literariness, on the other hand, innovative writing (either positively or negatively oriented) is regarded as appropriate and is actually expected. So creativity can be a fundamental contribution to the aesthetic dimension of a text of this kind.

The better a text is written, the more stable its SOM, and, in consequence, the more difficult it will be to translate it. Translation deals with texts individually, dissecting the 
SOM of the SL text in an attempt to rebuild a matching one in the target language. As a result it is bound to affect the dimensions of SOM in various degrees, regardless of the kind of language or the type of text. So far as translation is concerned, the aesthetic is useful as a general criterion, materialized in parameters such as communicative purpose (the relation between author/translator and reader), appropriateness (the relation between text and genre as institutionalized social mode of expression), and structural stability (the relation of the aesthetic with the other two within a text, i.e. the individuality of a text).

With the rise of communication theories in the twentieth century, a shift of emphasis from text to reader has marked contemporary thinking in translation studies. The phenomenon, noticed by some translation theorists (e.g. Newmark), indicates a progression from a single-dimensional perspective of pure linguistic concern (for instance, how to translate an adjective clause, etc.) to a two-dimensional approach to translation as information conveyance and acceptance. It implies, however, a tendency to ignore textual features of the SL text in favour of more ready acceptance of ideational content in a new linguistic, socio-cultural context. This, if carried too far, may become another version of one-dimensional understanding of translation which regards communicativeness as the only thing that matters in translating.

The application of communication theory to translation in our study, however, has led to an understanding of text in its three dimensions; and translation is viewed as a textbased (both SL and TL texts), translator-centred and reader-oriented performance aiming to construct in the target language a SOM that will match as much as possible the original one in the three dimensions. Translating is no longer a rude practice shedding off the "form" to pass on the "content."

It should be clear, therefore, that our purpose is firstly to bring the focus of attention back to the text(s), to the workings of translating as distinct from those of writing, and secondly to put the translator alongside the writer and the reader. This is meant to neutralize the "cult" of the reader's response in modern translation studies, in the interest of the TL readers themselves, by giving back to them the access to the world of the SL text; and to provide a ground for target-text oriented translators and source-text oriented translators to "bring their versions closer to each other's," as advocated by Newmark (1991:4).

\section{TRANSLATING: A THREE DIMENSIONAL PROCESS}

Theorists have found it not easy to define a translated text in relation to the original. The difficulty is typically seen in such a circumlocutory statement as Lattimore's (1959/66: 49), that a translation presents "what the original would be, might be, or ought to be, must be" in the target language. Descriptions via fuzzy metaphors, such as translation being "a living work" (Popovic 1970: 80), or "a living entity" (Bassnett-McGuire 1980: 70-71, talking about Edward Fitzgerald's translation of The Rubaiyat of Omar Khayyam (1858)) in the TL culture, border on an elusiveness and subjectivity similar to that in classical Chinese critical practice which shows more intuitive insights than analytic understanding, containing concepts that defy definition.

It is not, however, our purpose here to clarify the description, or prescription, of what a translation should look like, since translating as a process inevitably proceeds from the original text towards its (at least temporarily definite) end product in the form of a TL text. It is, therefore, probably of more interest to trace this process in a more analytic way, to see what the roads in a jungle of vying claims (linguistic and cultural) will lead a translator to. 


\section{IDIOMATIC AND CREATIVE USE OF LANGUAGE}

In the first dimension of the translating process, the translator deals with the lexicogrammatical system of both the source and the target languages, each of them organizes its perception of the world in its own way. Here, on the one hand, the translator has to work against structural and functional differences between the languages, a full recognition of which has yet to be given by modern linguistics. On the other hand, the translator believes in the (at least theoretically) infinite resources of the target language and his/her capability of and licence in using the language creatively, making sentences that may have never been heard, conveying ideas that may have never been articulated before in the language. This is the basis of cross-cultural translatability; it implies the possibility of deviation from idiomaticity in translating on not infrequent occasions.

It may be interesting for a translator to notice the alterations and fusions of canonical forms of idiomatic expressions among native English speakers in conversational discourse observed by Tannen (1989: 40-42), a linguistic phenomenon existing among native Chinese speakers as well, and certainly not uncommon in written texts. For instance, zhaixia ('cramped:narrow') is a fusion of zhaixiao ('cramped:small') and xia' ai ("narrow:limited'); liangtou shouyan ('being smoked at from both ends'-being blamed by both parties) is an altered form of the idiom liangtou shouqi ('being blown at from both ends') of the same meaning. Such petty ingenuity, unwitting though it may seem, can be, in Tannen's (1989) words, "a form of linguistic creativity rather than an error or misfire." Therefore, being idiomatic is not at odds with being creative and off-beat to claim the reader's attention. Idiomaticity and creativity are two complementary qualities of all good writing. If these qualities are desirable when one has something original to express in writing, they should also be prerequisites for translating, where one has to rewrite in a matching style what has been originally written in some other language at some other time.

\section{RESTORATION OF INFORMATION DISTRIBUTION}

Translating acquires its second dimension when, through the locutionary sense, the translator extracts the thought or the information he/she requires to get to the illocutionary message. Here lies the umbilical cord that links a translation to its original. If the truth value of the SL text is subject to the conditions governed by the reality of the world it belongs to, the TL text, in principle, can be true only to the reality of the same world. This world should be the one created or depicted in the SL text if it is a text of high literariness and thus of high text-sovereignty (see for instance Widdowson (1993) for the "non-accountability" of literary texts). And if the SL text is "utilitarian" in nature, then it is the objective world to which the TL text should be true via the SL text that acts as a constant reference or governing factor throughout the translating process to ensure the validity of the TL text.

To be faithful to the world and the illocutionary message of the SL text, translating in this dimension should seek to restore in the TL text the distribution of information in the SL text. A question worth asking is what is the author's communicative intention behind the arrangement of information units in the text. The organization of text as such links linguistic choices with discourse choices, and language uses (idiomatic or innovative) with socio-cultural conventions ( $c f$. McCarthy and Carter 1994: ch. 2, esp. sec. 2.4). Translating would be reduced to some general or even desultory rewriting, once severed from its SL origin in this dimension since, looking beyond this dimension, we can see that the other two dimensions of the TL text are just "reflections" of their SL counterparts, subjected to the filtering by the linguistic and cultural faculties of the target language, and above all, by those of the translator as a human being as well as an operator. 


\section{MATCHING THE EFFECT}

Since the second dimension of translation is so important, it tends to overshadow, unduly in most cases, the significance of the third. This happens when translating becomes more "communicative," which means the translator is more interested in informing the TL readers of rather than involving them in the world presented in the SL text, as in the case of modern Bible translation observed by Newmark (1981: 45). In so doing, the translator concentrates, more often than not, on the first two dimensions, or even the second one only. Although the translating of most texts is more communicative in nature, (of such "run-of-the-mill texts" Newmark (1991: 10) has given a long list), the project of reconstructing a matching TL SOM does require a process of three-dimensional translating.

In its third dimension translating manifests itself as an aesthetic activity, calling for a more active and creative involvement of the translator to feel for the SL text's perlocutionary effects in order to retain them in the TL text. It is in this sense that we say the third dimension of translating offers a chance for the translator's ability, talent, and originality. The perception of the original's aesthetic impact at this juncture becomes very important although the realization of such an impact in the TL text is better appreciated in line with the TL cultural orientation.

In this analysis, the three-dimensional process of translating is actually a dynamic, cross-cultural channel with two matching SOMs at the ends. The first dimension of the translation process, mechanical in practical exertion and eventually comparable between the SL text and its TL counterpart(s) provides a field for manoeuvre of the target language's linguistic resources. The second dimension, having to do with information distribution on various levels, lends itself to measurable truth conditions which may determine the successfulness of conveyance of propositional message. In the third dimension, however, with greater involvement of the translator and the reader, translating becomes more personal, emotional, and more like an art than a science. As Lefèvre (1975: 99) points out, "unsatisfactory renderings of the source text [...] all concentrate exclusively on one aspect of the source text only, rather than on its totality." A translating process which fails to take account of the three dimensions of the original text, can only turn out a translation as a distorted reflection of the original in the linguistic and cultural environment of the target language.

\section{CONCLUSION}

Our study is premised on the notion that textual comparison is one of the key approaches to translation studies. The crucial move then is to identify the textual properties (of the SL text and its TL counterpart(s)) that are comparable and have to be compared, in order to obtain a critical insight into the actualization of a TL text. For this purpose we have done a brief analysis of the tri-stratal system of functional grammar with special attention on the three components of the semantic system, i.e., the ideational, the interpersonal and the textual, from the point of view of translation. We found that a functional model as such explains the nature of language in the formation of a text, but it does not have much to say about the intention and effect of the creation of a text which, in our view, are vital to the aesthetic aspect of translation studies. In our effort to establish a more comprehensive model for the study of translation and translating, we also had recourse to the theory of speech act, which deals with issues such as intention, effect and communicative achievement in language use, by observing the three types of speech act, that is, locutionary act, illocutionary act and perlocutionary act. We found it complementary to the model of functional grammar. 
After a comparative study of the two models, we have attempted to establish a new and more comprehensive three-dimensional model-Structure of Meaning-which is a combination of the first two. In this way we are able to focus our attention on the three dimensions that are comparable and should be compared, i.e., linguistic composition, interactional dynamic and aesthetic impact, in the process of translating. We argue that textual meaning should be viewed as a structure of these three dimensions not as a twodimensional "area" or "pattern."

An observation of the relation between the three dimensions has revealed a fundamental connection between text and genre in the guise of proportionate importance of each dimension to the others in the framework of Structure of Meaning. Such an understanding in turn throws some new light on the interaction between "form" and "meaning." Both issues, genre and "form" and "meaning," are among the basics in any functional study of translation.

The three-dimensional nature of Structure of Meaning, in our study, has pointed to the fact that translating is a three-dimensional process. In this sense, the nature of text formation in translating is seen as an operation of information management to create a new structure of meaning in the target language to match the original one in the source language in all those dimensions.

The present study has demonstrated our initial effort to clarify some theoretical issues of translation of text, which have been surfacing with the development of disciplines such as discourse analysis and text linguistics. We understand that much more effort is needed to depict the model of Structure of Meaning in greater detail so as to facilitate exploration of textual meaning for translating. We hope our discussion will draw due attention to the theoretical significance of the practice of textual translation.

Note

1. This article is adapted from the first chapter of Structure of Meaning (SOM): towards a three-dimensional perspective on translating between Chinese and English (Nottingham, 1993), a thesis submitted to the University of Nottingham, UK, for the degree of Doctor of Philosophy.

\section{REFERENCES}

AUSTIN, J. L. (1975) : How to Do Things with Words, (the William James Lectures in 1955), Oxford, Clarendon Press.

BASSNETT-MCGUIRE, Susan (1980) : Translation Studies, London and New York, Methuen.

BELL, Roger (1991) : Translation and Translating: Theory and Practice, London and New York, Longman.

COULTHARD, Malcolm (1985) : An Introduction to Discourse Analysis, London and New York, Longman.

DRIĖRE, C. L. (1957) : "Structure, Sound and Meaning", Northrop Frye (Ed.), Sound and Poetry, New York and London, Columbia University Press, pp. 85-108.

HALLIDAY, M. A. K. (1973) : Explorations in the Functions of Language, London, Edward Arnold.

HALLIDAY, M. A. K. (1978) : Language as Social Semiotic: the Social Interpretation of Language and Meaning, London, Edward Amold.

HALLIDAY, M. A. K. (1985) : An Introduction to Functional Grammar, London, Edward Arnold.

HATIM, Basil and Ian MASON (1990) : Discourse and the Translator, London and New York, Longman.

HOLMES, J. S. (1988) : Translated! Papers on Literary Translation and Translation Studies, Amsterdam, Rodopi.

LATTIMORE, R. (1959/66) : "Practical Notes on Translating Greek Poetry", R. A. Brower (Ed.), On Translation, New York, Oxford University Press, pp. 48-56.

LAWENDOWSKI, B. P. (1978) : "On Semiotic Aspects of Translation", Thomas A. Sebeok (Ed.), Sight, Sound, and Sense, Bloomington and London, Indiana University Press.

LEFÈVRE, André (1975) : Translating Poetry - Seven Strategies and a Blueprint, Assen/Amsterdam, Van Gorcum.

MCCARTHY, Michael (1991) : Discourse Analysis for Language Teachers, Cambridge, Cambridge University Press.

MCCARTHY, Michael and Ronald CARTER (1994) : Language as Discourse: Perspectives for Language Teaching, Harlow, Longman.

NEWMARK, Peter (1981) : Approaches to Translation, Oxford, New York, etc, Prentice Hall. 
NEWMARK, Peter (1991) : About Translation, Clevedon, etc., Multilingual Matters.

NIDA, E. A. (1964) : Toward a Science of Translation: with Special Reference to Principles and Procedures Involved in Bible Translating, Leiden, Brill.

NIDA, E. A. and C. R. TABER (1969) : The Theory and Practice of Translation, Leiden, United Bible Societies.

POPOVIC, A. (1970): "The Concept 'Shift of Expression' in Translation Analysis", J. S. Holmes (Ed.), The Nature of Translation, The Hague and Paris, Mouton, pp. 78-87.

RICHARDS, I. A. (1953) : "Toward a Theory of Translating", Arthur F. Wright (Ed.), Studies in Chinese Thought, Chicago, the University of Chicago Press, pp. 247-262.

RODWAY, Allan (1982) : The Craft of Criticism, Cambridge, Cambridge University Press.

RUSSO, John Paul (1989) : I.A. Richards: his Life and Work, London, Routledge.

SEARLE, John R. (1969) : Speech Acts: an Essay in the Philosophy of Language, London, Cambridge University Press.

TANNEN, Deborah (1989) : Talking Voices: Repetition, Dialogue, and Imagery in Conversational Discourse, Cambridge, etc., Cambridge University Press.

WIDDOWSON, H. G. (1993) : "Representations in Prose: Setting the Scene", John M. Sinclair et al. (Eds), Techniques of Description: Spoken and Written Discourse: a Festschrift for Malcolm Coulthard, London and New York, Routledge. 